\title{
An Adaptive Neuro-Fuzzy Speed Controller for a Separately excited DC Motor
}

\author{
Basma A. Omar \\ Computer Eng, and systems \\ department, Faculty of \\ engineering, Mansoura \\ University, Egypt.
}

\author{
Amira Y. Haikal \\ Computer Eng, and systems \\ department, Faculty of \\ engineering, Mansoura \\ University, Egypt.
}

\author{
Fayz F. Areed \\ Computer Eng, and systems \\ department, Faculty of \\ engineering, Mansoura \\ University, Egypt.
}

\begin{abstract}
In this paper an Adaptive Neuro Fuzzy Inference System (ANFIS) controller using error and derivative of error inputs is proposed for the speed control of a separately excited dc motor (SEDCM) using chopper circuit. This paper investigates the design and simulation of an adaptive Neuro-Fuzzy Inference System (ANFIS) controller for the speed of a DC motor. The performance of the proposed system has been compared with conventional one, where the conventional PI controller ( speed controller ) in the ChopperFed DC Motor Drive is replaced by the adaptive Neuro-Fuzzy controller to improve the dynamic behavior of the model. Computer Simulation is conducted to demonstrate the performance of the proposed controller and results show that the proposed design succeeded over the conventional PI controller where it enhances dynamic responses and reduce ripples. Moreover, results of comparing the proposed ANFIS controller with other related work is improved. The entire system is modeled using MATLAB 2009 toolbox.
\end{abstract}

\section{General Terms}

Artificial intelligence, Control.

\section{Keywords}

adaptive neuro-fuzzy inference, Chopper Circuit, SEDCM, Speed control.

\section{INTRODUCTION}

Direct current (DC) motors have been widely used in many industrial applications such as electric vehicles, steel rolling mills, electric cranes, and robotic manipulators due to precise, wide, simple, and continuous control characteristics. Traditionally armature control method was widely used for the speed control of low power dc motors. However the controllability, cheapness, higher efficiency, and higher current carrying capabilities of static power converters brought a major change in the performance of electrical drives. The desired torque-speed characteristics could be achieved by the use of conventional proportional integralderivative (PID) controllers. However, PID controllers require exact mathematical model. The Adaptive Neuro-Fuzzy Inference System (ANFIS), developed in the early 90s by Jang [1], combines the concepts of fuzzy logic and neural networks to form a hybrid intelligent system that enhances the ability to automatically learn and adapt. Hybrid systems have been used by researchers for modeling and predictions in various engineering systems. The basic idea behind these neuro-adaptive learning techniques is to provide a method for the fuzzy modeling procedure to learn information about a data set, in order to automatically compute the membership function parameters that best allow the associated FIS to track the given input/output data. The membership function parameters are tuned using a combination of least squares estimation and back-propagation algorithm. These parameters associated with the membership functions will change through the learning process similar to that of a neural network. Their adjustment is facilitated by a gradient vector, which provides a measure of how well the FIS is modeling the input/output data for a given set of parameters. Once the gradient vector is obtained, any of several optimization routines could be applied in order to adjust the output so as to reduce error between the actual and desired outputs. This allows the fuzzy system to learn from the data it is modeling. This approach has the advantage over the pure fuzzy paradigm in which the need for the human operator to tune the system by adjusting the bounds of the membership functions is removed. The aim of this paper is to simulate a speed control system [2] that can predict the dynamic behaviors of a DC motor fed by chopper circuit. The superior performance of artificial intelligence (AI) based controllers urged power system and power electronic engineers to replace conventional speed control circuit with intelligent speed controllers $[3,4]$. To test the validity of the proposed controller, it is tested against speed and load variation and compared to other conventional and intelligent controllers. Moreover, parameter variation is also studied, where the armature winding resistance is changed and the results are discussed.

This paper consists of six sections, where section 2 illustrates the DC motor model. Section 3 describes the modeling and control of SEDCM using MATLAB SimPowerSystems. Section 4 describes the ANFIS controller involved. Section 5 presents simulation results for speed control using ANFIS controller and comparison with other conventional intelligent controllers is conducted taking into account speed, load resistance variation.

\section{MODLING OF DC MOTOR}

The DC motor is the obvious proving ground for advanced control algorithms in electric drives due to the stable and straight forward characteristics associated with it. It is also ideally suited for trajectory control applications. From a control systems' point of view, the DC motor can be considered as SISO plant, thereby eliminating the complications associated with a multi-input drive system [5]. 


\subsection{Dynamics of DC Motor}

Dynamics of a DC motor is described by the following equations:

$$
\begin{aligned}
& K_{P} \omega(t)=-R i(t)-L \frac{d i(t)}{d t}+V(t) \\
& K_{t} i(t)=J \frac{d \omega(t)}{d t}+D \omega(t)-T_{L}(t)-T_{F}(\omega) \\
& T_{F}(\omega)=\alpha \sin (\omega)
\end{aligned}
$$

Where, the parameters of the DC motor are shown in Table 1. In order to control a plant, a discrete time model of the plant is required. The following discrete time model of a DC motor is used:

$V(K)=A_{1} \omega(K+1)+A_{2} \omega(K)+A_{3} \omega(K-1)$

$+A_{4}(K, K-1)$

Where $\mathrm{k}$ indicates the $\mathrm{k}^{\text {th }}$ discrete time moment, $\mathrm{A}_{1}, \mathrm{~A}_{2}$, and $\mathrm{A}_{3}$ are real constants, and $\mathrm{A}_{4}$ is a real parameter which depends on the load of the motor [3].

\subsection{Chopper fed-DC motor drive}

A DC motor consists of stator and armature winding in the rotor (see figure 1). The armature winding is supplied with a DC voltage that causes a DC current to flow in the winding.

Table1: DC motor's parameters.

\begin{tabular}{|c|c|c|c|}
\hline No & Definition & Symbols & unit \\
\hline 1 & Rotor speed & $\omega(\mathrm{t})$ & $\mathrm{rad} \mathrm{s}^{-1}$ \\
\hline 2 & armature resistance & $\mathrm{R}$ & $\Omega$ \\
\hline 3 & $\begin{array}{c}\text { Armature } \\
\text { inductance }\end{array}$ & $\mathrm{L}$ & $\mathrm{H}$ \\
\hline 4 & Armature current & $\mathrm{i}(\mathrm{t})$ & $\mathrm{A}$ \\
\hline 5 & Armature voltage & $\mathrm{V}(\mathrm{t})$ & $\mathrm{V}$ \\
\hline 6 & $\begin{array}{c}\text { load torque } \\
\mathrm{T}_{\mathrm{L}}\end{array}$ & $\mathrm{Nm}^{-}$ \\
\hline 7 & $\begin{array}{c}\text { Rotor inertia } \\
8\end{array}$ & $\mathrm{~J}$ & $\mathrm{~kg} \mathrm{~m}^{2}$ \\
\hline 9 & $\begin{array}{c}\text { Torque constant } \\
\text { Back EMF constant }\end{array}$ & $\mathrm{K}_{\mathrm{t}}$ & $\mathrm{V} \mathrm{s} \mathrm{rad}^{-1}$ \\
\hline 10 & $\begin{array}{c}\text { Viscous friction } \\
\text { coefficient }\end{array}$ & $\mathrm{D}$ & $\mathrm{V} \mathrm{s} \mathrm{rad}^{-1}$ \\
\hline 11 & $\begin{array}{c}\text { Coulomb friction } \\
\text { torque }\end{array}$ & $\mathrm{T}_{\mathrm{F}}$ & $\mathrm{Nms} \mathrm{rad}^{-1}$ \\
\hline 12 & $\begin{array}{c}\text { Positive constant } \\
\alpha\end{array}$ \\
\hline
\end{tabular}

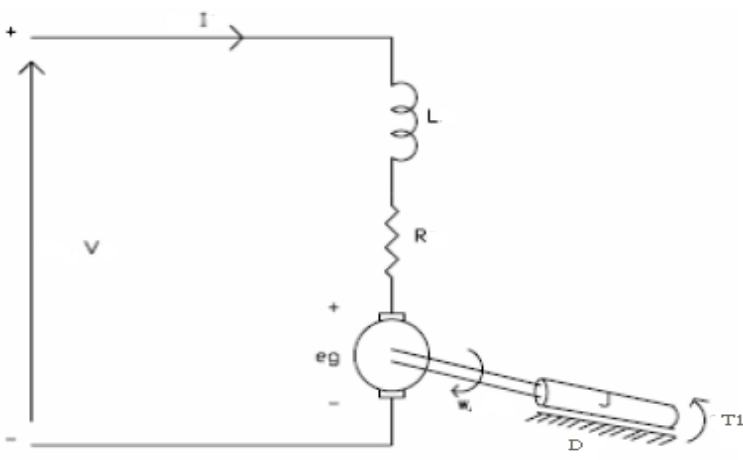

Fig 1: Dynamic equivalent circuits of a DC motor.

The field circuit of the motor is excited by a constant source. The steady state speed of the motor can be described as:

$\omega=\frac{V-i R}{k_{1}}$

Where $\mathrm{k} 1$ is the duty cycle. The speed of a DC motor can be controlled by varying the voltage applied to the terminal. These can be done by using a pulse-width modulation (PWM) technique (see figure 2), where $\mathrm{T}$ is the signal period, td is the pulse-width, and $\mathrm{V}_{\mathrm{m}}$ is the signal amplitude. A field voltage signal with varying pulse-width is applied to the motor terminal. The average voltage is calculated from

$V a g=\frac{1}{T} \int_{0}^{T} V(t) d t=\frac{t d}{T} V m=K_{1} V m$

It can be mentioned from these equation that the average DC component of the voltage signal is linearly related to the pulse-width of the signal, or the duty cycle of the signal, since the period is fixed.

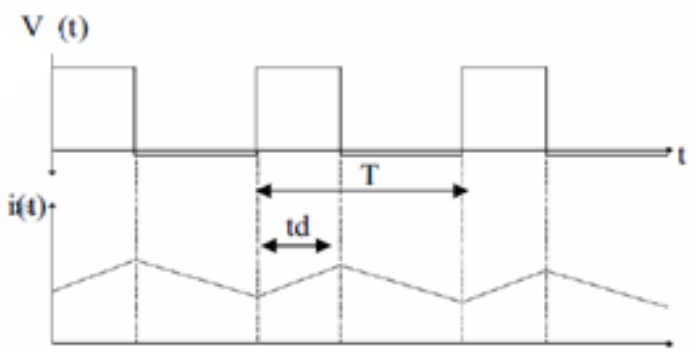

Fig 2: Pulse width modulation.

The PWM voltage waveform for the motor is to be obtained by using a special power electronic circuit called a DC chopper. The action done by the DC chopper is supplying a train of unidirectional voltage pulses to the armature winding of the PM-DC motor as shown on figure 2. If td is varied keeping $\mathrm{T}$ constant, the resultant voltage wave represents a form of pulse width modulation, and hence the chopper is named as the PWM chopper [6, 7]. 


\section{MODELING AND CONTROL OF SEDCM USING MATLAB SIMPOWERSYSTEMS}

Figure 3. Shows MATLAB/SimPowerSystems model of a separately excited DC motor which has been selected to control [8]. It consists of a separately excited dc motor fed by a DC source through a chopper circuit. A single GTO thyristor with its control circuit and a free-wheeling diode form the chopper circuit. The motor drives a mechanical load characterized by inertia $\mathrm{J}$, friction coefficient $\mathrm{B}$, and load torque $\mathrm{T}_{\mathrm{L}}$. The control circuit consists of a speed control loop and a current control loop. A proportional-integral (PI) speed control loop senses the actual speed of the motor and compares it with the reference speed to determine the reference armature current required by the motor. One may note that any variation in the actual speed is a measure of the armature current required by the motor. The current control loop consists of a hysteresis current controller (HCC). The block diagram of a hysteresis current controller is shown in Figure 4. HCC is used to generate switching patterns required for the chopper circuit by comparing the actual current being drawn by the motor with the reference current. A positive pulse is generated if the actual current is less than reference armature current, whereas a negative pulse is produced if the actual current exceeds reference current [9]. In this paper, an Adaptive Neuro-Fuzzy Inference System (ANFIS) controller has been proposed for the speed control of separately excited DC motor in the constant torque region, which is detailed in the following part of this paper.

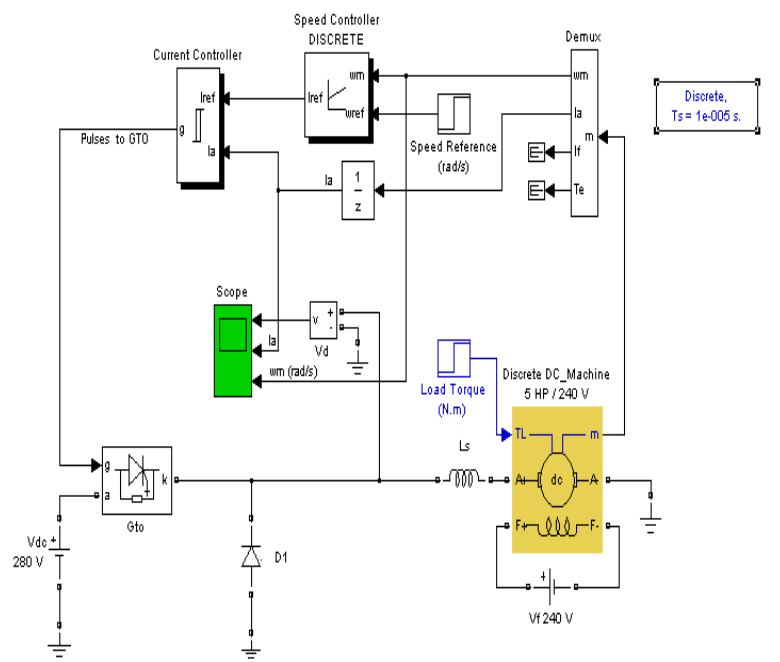

Fig 3 : MATLAB/SimPowerSystems model of a separately excited DC motor speed control.

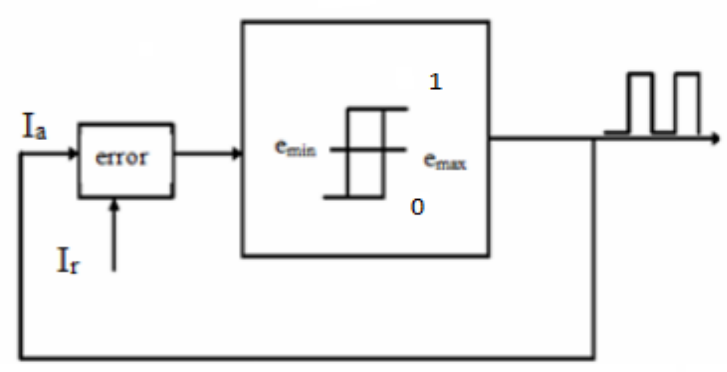

Fig.4: Block Diagram of a hysteresis current controller.

\section{ADAPTIVE NEURO-FUZZY MODE SPEED CONTROLLER}

\subsection{Adaptive Neuro-fuzzy principle}

A typical architecture of an ANFIS is shown in Figure 5., in which a circle indicates a fixed node, whereas a square indicates an adaptive node. For simplicity, we consider two inputs $\mathrm{x}, \mathrm{y}$ and one output $\mathrm{z}$. Among many FIS models, the Sugeno fuzzy model is the most widely applied one for its high interpretability and computational efficiency [10]. For a first order Sugeno fuzzy model, a common rule set with two fuzzy if-then rules can be expressed as:

Rule 1:

if $\mathrm{x}$ is $\mathrm{A} 1$ and $\mathrm{y}$ is $\mathrm{B} 1$, then

$$
\mathrm{z} 1=\mathrm{p} 1 \mathrm{x}+\mathrm{q} 1 \mathrm{y}+\mathrm{r} 1
$$

Rule 2:

$$
\text { if } \mathrm{x} \text { is } \mathrm{A} 2 \text { and } \mathrm{y} \text { is } \mathrm{B} 2 \text {, then }
$$

$$
\mathrm{z} 2=\mathrm{p} 2 \mathrm{x}+\mathrm{q} 2 \mathrm{y}+\mathrm{r} 2
$$

Where $\mathrm{Ai}$ and $\mathrm{Bi}$ are the fuzzy sets in the antecedent, and $\mathrm{p}_{\mathrm{i}}, \mathrm{q}_{\mathrm{i}}$ and $r_{i}$ are the design parameters that are determined during the training process. As shown in figure 5, the ANFIS consists of five layers $[10,11]$.

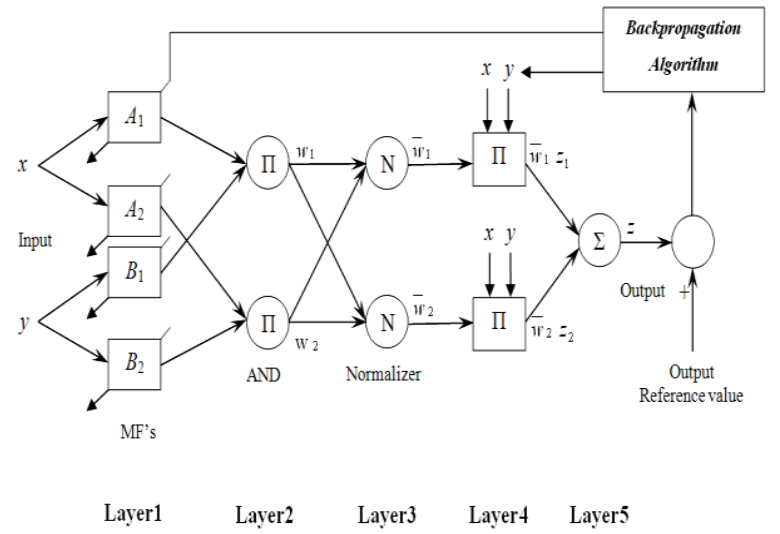

Fig 5:Corresponding ANFIS Architecture.

The task done by each layer is explained next.

Layer 1: Is composed of a number of computing nodes whose activation functions are fuzzy logic membership functions (triangular functions).

Layer 2: Chooses the minimum value of the inputs.

Layer 3: Normalizes each input with respect to the others (The $\mathrm{i}^{\text {th }}$ node output is the $\mathrm{i}^{\text {th }}$ input divided by the sum of all the other inputs).

Layer 4: $\mathrm{i}^{\text {th }}$ node output is a linear function of the third layer's $\mathrm{i}^{\text {th }}$ node output and the ANFIS input signals.

Layer 5: Sums all the incoming signals. The ANFIS structure can be tuned automatically by a least-square estimation (for output membership functions) and a back propagation algorithm (for output and input membership functions) [11]. 


\subsection{Adaptive Neuro-Fuzzy controller}

The ANFIS controller generates change in the reference voltage $V_{\text {ref }}$, based on speed error e and derivative in the speed error $\Delta \mathrm{e}$ defined as:

$e(t)=\omega_{r e f}-\omega$

$\Delta e(t)=\left[d\left(\omega_{r e f}-\omega\right)\right] / d t$

Where $\omega_{\text {ref }}$ and $\omega$ are the reference and the actual speeds. In this study first order Sugeno type fuzzy inference is used for ANFIS and the typical fuzzy rule is:

If $\mathrm{e}$ is $\mathrm{A}_{\mathrm{i}}$ and de is $\mathrm{B}_{\mathrm{i}}$ then $\mathrm{z}=\mathrm{f}(\mathrm{e}$, de)

Where $A_{i}$ and $B_{i}$ are fuzzy sets in the antecedent and $z=f(e$, de) is a crisp function in the consequent.

The significances of ANFIS structure are:

Layer 1: Each adaptive node in this layer generates the membership grades for the input vectors $a_{i}, i=1,2,3$. In this paper, the node function is a triangular membership function:

$$
O_{i}^{1}=\mu_{A_{1}}(e)= \begin{cases}0 & e \leq a_{i} \\ \frac{e-a_{i}}{b_{i}-a_{i}} & a_{i} \leq e \leq b_{i} \\ \frac{e_{i}-e}{e_{i}-b_{i}} & b_{i} \leq e \leq b_{i} \\ 0 & e_{i} \leq e\end{cases}
$$

Layer 2: The total number of rule is nine in this layer. Each node output represents the activation level of a rule

$O_{i}^{1}=W_{i}=\min \left(\mu_{A_{i}}(e) \cdot \mu_{B_{i}}(e)\right)$

Layer 3: Fixed node $i$ in this layer calculates the ratio of the $\mathrm{i}^{\text {th }}$ rule's activation level to the total of all activation level:

$$
O_{i}^{3}=\bar{W}_{i}=\frac{W}{\sum_{j=1}^{n} W_{J}}
$$

Layer 4: Adaptive node $\mathrm{i}$ in this layer calculates the contribution of $\mathrm{i}^{\text {th }}$ rule towards the overall output, with the following node function:

$$
O_{i}^{4}=\bar{W}_{i} Z_{i}=\bar{W}_{i}\left(P_{i} e+q_{i} d e+r_{i}\right)
$$

Layer 5: The single fixed node in this layer computes the overall output as the sum of each rule's contribution.

$$
O_{i}^{5}=\sum_{i=1}^{2} \overline{W_{i}} Z_{i}=\frac{W_{1} Z_{1}+W_{2} Z_{2}}{W_{1}+W_{2}}
$$

The parameters to be trained are $a_{i}, b_{i}$ and $c_{i}$ of the premise parameters and $p_{i}, q_{i}$,and $r_{i}$ of the consequent parameters.
A flow chart describing the proposed methodology is illustrated in figure 6 .

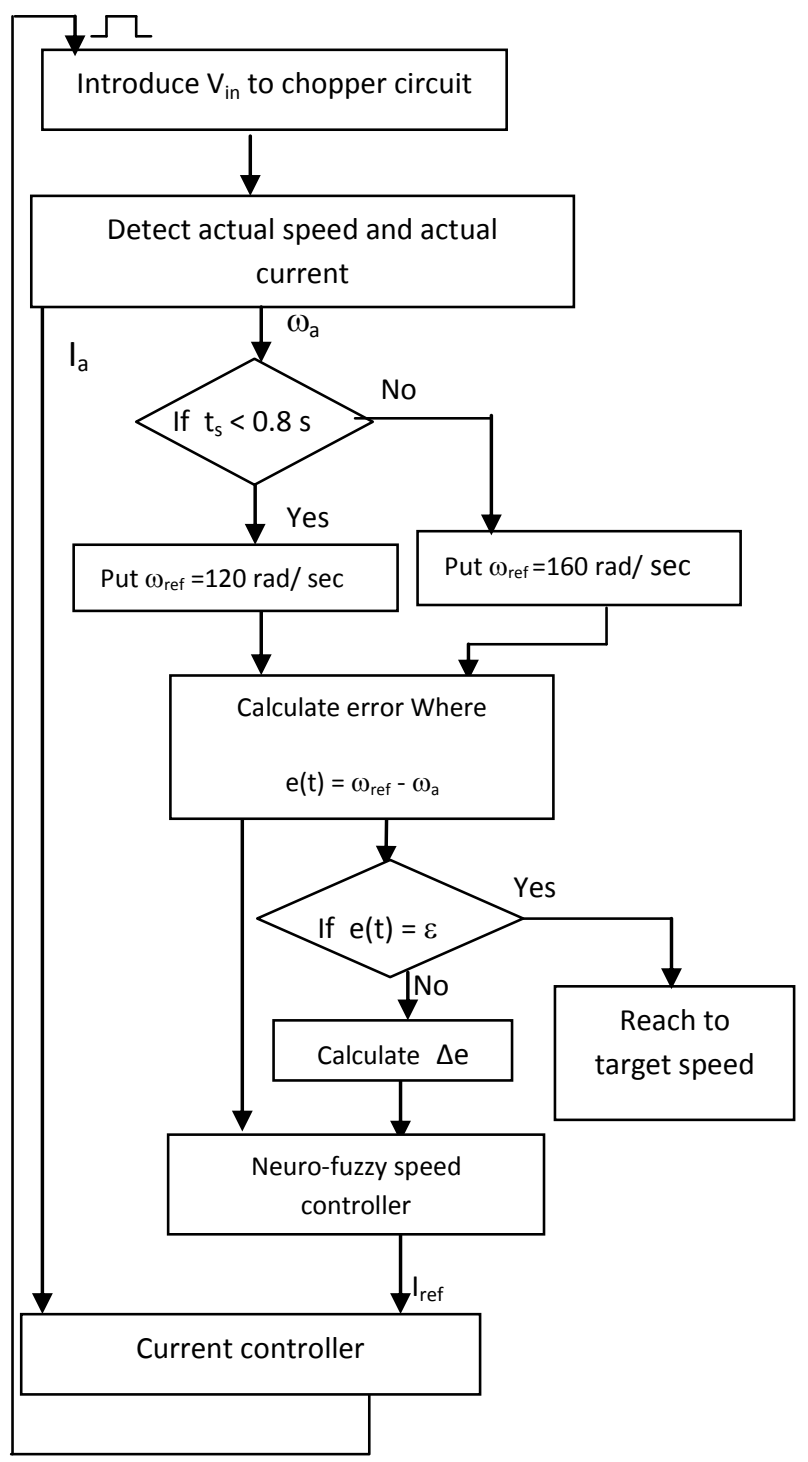

Fig 6.:A flow chart describing the proposed methodology.

\section{SIMULATION RESULT OF SPEED NEURO-FUZZY CONTROLLER}

An Adaptive Neuro Fuzzy Inference System (ANFIS) controller is simulated for chopper fed-DC motor drive with parameters as shown in Table 2. The number of epochs is 150 for training. The number of MFs for the input Variables e and $\Delta \mathrm{e}$ is 3 and 3 . The number of rules is then $9(3 * 3=9)$. The triangular MF is used for two input variables. It is clear from eq(11) that the triangular MF is specified by two parameters.

Therefore, the ANFIS used here contains a total of 39 fitting parameters, of which $12(2 * 3+2 * 3=12)$ are the premise parameters and $27(3 * 9=27)$ are the consequent Parameters. Figure 7. shows the ANFIS model structure involved in this work. 
Table 2. Definition of parameters and its value.

\begin{tabular}{|c|c|c|c|}
\hline No & Definition & Symbols & Data/unit \\
\hline 1 & Shaft power & $\mathrm{P}$ & $5 \mathrm{hp}$ \\
\hline 2 & Rated Voltage & $\mathrm{v}$ & $240(\mathrm{rms}) \mathrm{V}$ \\
\hline 3 & $\begin{array}{c}\text { Armature } \\
\text { resistance }\end{array}$ & $\mathrm{R}_{\mathrm{a}}$ & $0.6 \Omega$ \\
\hline 4 & $\begin{array}{c}\text { Armature } \\
\text { inductance }\end{array}$ & $\mathrm{L}_{\mathrm{a}}$ & $0.012 \mathrm{H}$ \\
\hline 5 & Field resistance & $\mathrm{R}_{\mathrm{f}}$ & $240 \mathrm{H}$ \\
\hline 6 & Field inductance & $\mathrm{L}_{\mathrm{f}}$ & 120 \\
\hline 7 & $\begin{array}{c}\text { Moment of } \\
\text { inertia }\end{array}$ & $\mathrm{J}$ & $0.05 \mathrm{kgm}^{2}$. \\
\hline 8 & $\begin{array}{c}\text { Viscous friction } \\
\text { coefficient }\end{array}$ & $\mathrm{B}$ & $0.2 \mathrm{Nms}$ \\
\hline 9 & $\begin{array}{c}\text { Coulomb } \\
\text { friction torque }\end{array}$ & $\mathrm{T}_{\mathrm{F}}$ & $0.5 \mathrm{Nm}$ \\
\hline
\end{tabular}

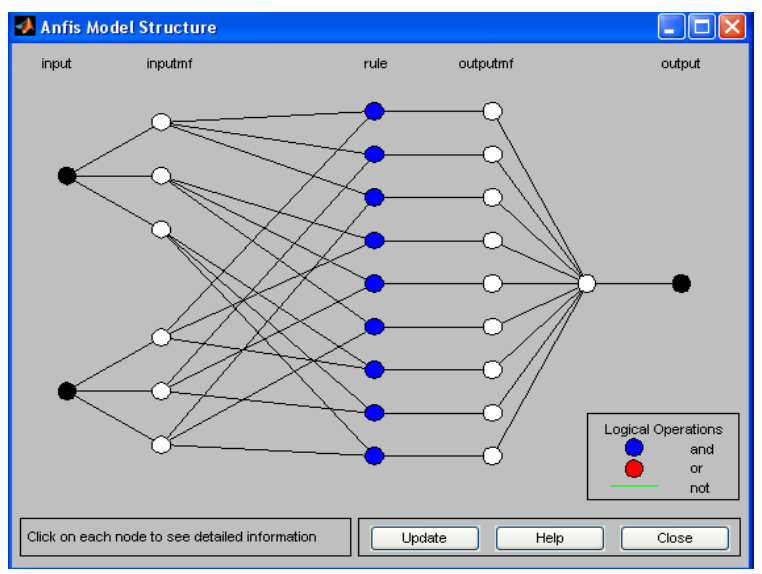

Fig 7: The ANFIS controller structure

After conducting the proposed chopper fed DC motor controlled by ANFIS, the optimized MFs for e and $\Delta \mathrm{e}$ after training is shown in figure 8.a,b.

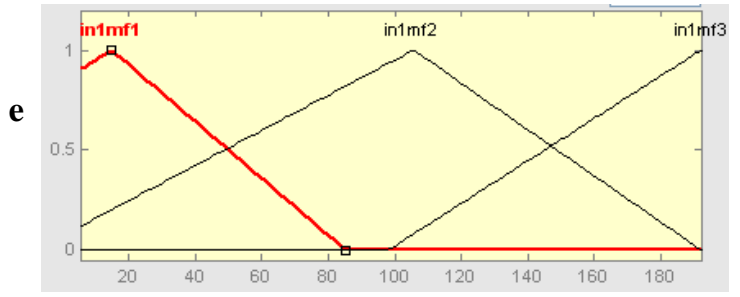

(a)

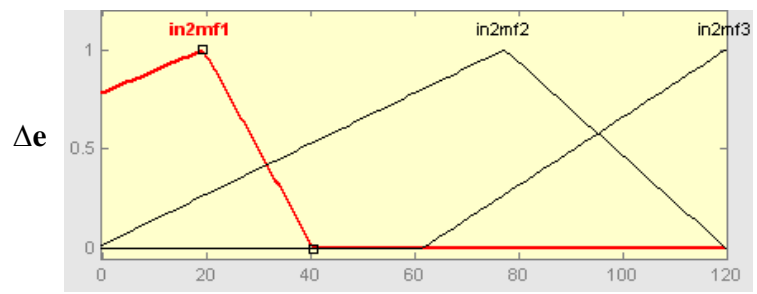

(b)

Fig 8: Membership function for (a) speed error signal (b) derivative of speed error signal.

\subsection{Simulation of ANFIS model compared with PI and FPID controller}

The model chosen here for simulation[8] is simulated and compared to the Conventional PI controller. Moreover, this simulation conducted for ANFIS and PI is compared to FPID controller[12].Where Algreer et. al., proposed the design of a fuzzy self-tuning for a PID controller where the proportional, integral and derivate (KP, KI, KD) gains in a system can be self-tuned on-line with the output of the system under control, the conventional PI controller (speed controller) in the Chopper-Fed DC motor Drive is replaced by the selftuning FPID controller[12].

Figure 9. shows model of a separately excited dc motor speed control with ANFIS and figure10. shows the internal model of ANFIS controller.

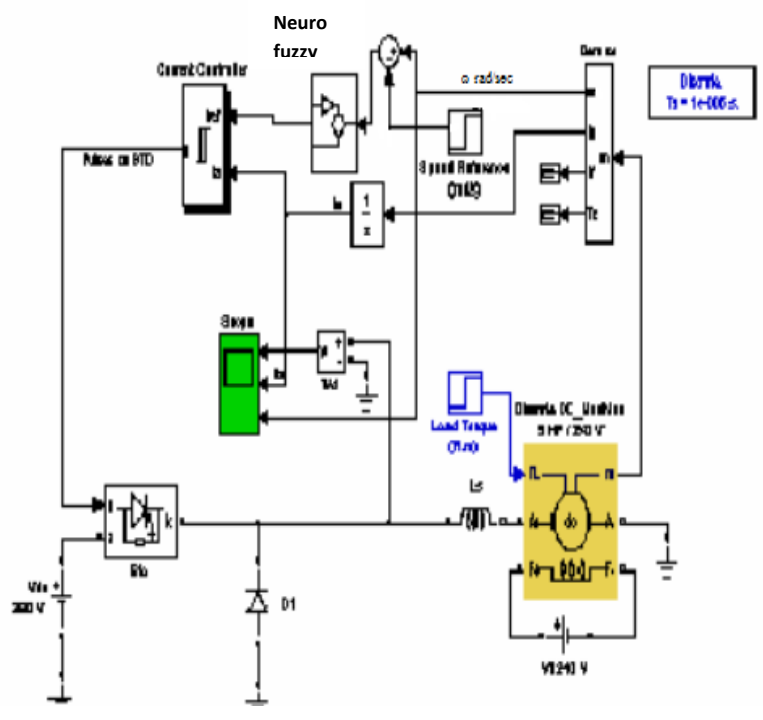

Fig 9:Model of a separately excited DC motor speed control with (ANFIS).

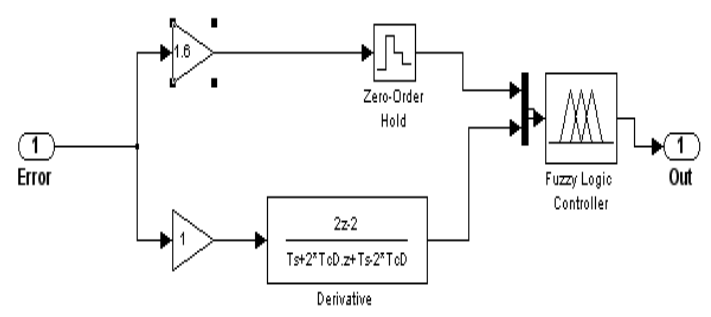

Fig 10.:Internal model of ANFIS controller.

Also, following observations can be made:

Starting the simulation and observing the motor voltage $\left(\mathrm{V}_{\mathrm{a}}\right)$, current $\left(I_{a}\right)$ and speed $(\omega)$ on the scope, where for $0<t<0.8$ $\mathrm{s}$ ( starting and steady state operation) and during this period, the load torque is $\mathrm{TL}=5 \mathrm{~N} . \mathrm{m}$.

(1) For $\mathrm{t}=0.8 \mathrm{sec}$ : Reference Speed Step:

The reference speed is increased from $120 \mathrm{rad} / \mathrm{s}$ to $160 \mathrm{rad} / \mathrm{s}$. The ANFIS speed controller regulates the speed in $\approx 0.04 \mathrm{~s}$. 
However, when comparing this result with PI speed controller speed regulation is approximately $0.25 \mathrm{~s}$ while using FPID $[12]$ it was $\approx 0.07$.

(2) For t = $1.5 \mathrm{~s}$ : Load Torque Step:

When the load torque is suddenly increased from 5 N.m to 25 N.m [8] the speed is nearly constant for ANFIS, however for PI and FPID [12] the speed is badly affected. Simulation results and comparisons prove that ANFIS performs with an acceptable response where rise time $=0.08 \mathrm{sec}$, at $\mathrm{t}=0.8 \mathrm{sec}$ (when the reference speed is increased), while for PI speed controller $=0.24 \mathrm{sec}$ and for FPID [12] speed controller $=0.2$ sec.

Table 3. illustrates comparison analysis regarding rise time and speed regulation between proposed ANFIS controller and both PI,FPID [12] controllers. While Table 4 illustrates the response before and after load variation and the appearance of overshoot for the three previously mentioned controllers ANFIS,FPID [12] and PI. The speed response for both PI and ANFIS controller are shown in figure $(11,12)$.

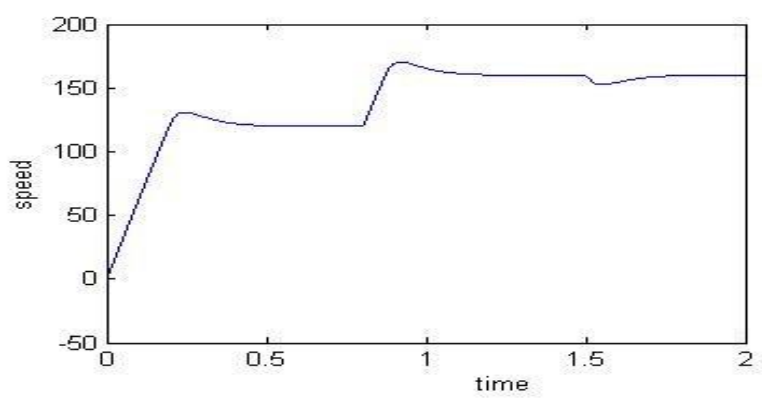

Fig11:Speed response of (PI) controller.

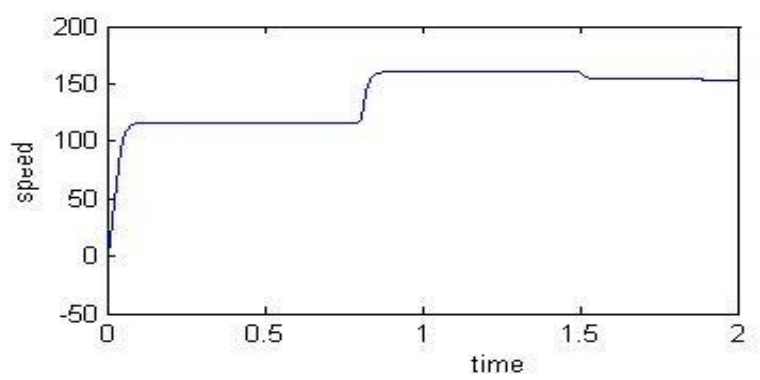

Fig12:.Speed response of (ANFIS) controller.

Table 3: comparison results between PI, FPID, and ANFIS controllers(speed variation).

\begin{tabular}{||c|c|c|}
\hline $\begin{array}{c}\text { Control } \\
\text { strategies }\end{array}$ & Rise time & $\begin{array}{c}\text { Time for speed } \\
\text { regulation }\end{array}$ \\
\hline $\begin{array}{c}\text { Conventional } \\
\text { PI }\end{array}$ & $0.24 \mathrm{sec}$ & $0.1 \mathrm{sec}$ \\
\hline $\begin{array}{c}\text { FPID } \\
{[12]}\end{array}$ & $0.2 \mathrm{sec}$ & $0.07 \mathrm{sec}$ \\
\hline ANFIS & $0.08 \mathrm{sec}$ & $0.04 \mathrm{sec}$ \\
\hline
\end{tabular}

Table 4: comparison results between PI, FPID, and ANFIS controllers(load change).

\begin{tabular}{||c|c|c|c|}
\hline $\begin{array}{c}\text { Control } \\
\text { strategies }\end{array}$ & $\begin{array}{c}\text { Settling time } \\
\text { before } \\
\text { changing } \\
\text { load }\end{array}$ & $\begin{array}{c}\text { Settling } \\
\text { time after } \\
\text { changing } \\
\text { load }\end{array}$ & overshoot \\
\hline $\begin{array}{c}\text { Conventional } \\
\text { PI }\end{array}$ & $0.58 \mathrm{sec}$ & $0.2 \mathrm{sec}$ & yes \\
\hline $\begin{array}{c}\text { FPID } \\
\text { [12] }\end{array}$ & $0.2 \mathrm{sec}$ & $0.2 \mathrm{sec}$ & no \\
\hline ANFIS & $0.09 \mathrm{sec}$ & $0.02 \mathrm{sec}$ & no \\
\hline
\end{tabular}

\subsection{Simulation of ANFIS model compared with NARMA-L2 controller}

The proposed ANFIS is conducted again changing speed reference to $(100-120 \mathrm{rad} / \mathrm{s})$, load torque from $(\mathrm{TL}=5 \mathrm{Nm}$ to $17 \mathrm{Nm}$ ) and the result is compared to NARMA-L2 controller proposed by [13]. Where, Moleykutty et. al., proposed NARMA- L2 controller (ANN) as speed control of SEDCM and eliminated the chopper circuit and its control circuit . Moleykutty et. al., Compared their work with two other systems; one with SimPower Systems (wap) based chopper controlled DC motor model and the other one using simulink model(was) based on PI controller [13]. The comparison between NARMA-L2controller and ANFIS controller are shown in Table 5,6 where speed and load is changed at the same time at $\mathrm{t}=8 \mathrm{~s}$. Figure 13.illustrates the ANFIS speed response.

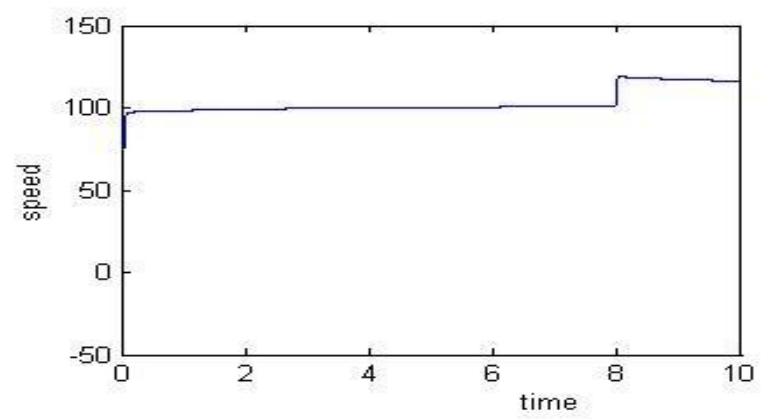

Fig13: Speed response of (ANFIS) controller.

Table 5. Comparison results between proposed ANFIS controller and NARMA-L2 controller.

\begin{tabular}{||c|c|c|c|c|}
\hline \hline $\begin{array}{c}\text { Control } \\
\text { strategies }\end{array}$ & $\begin{array}{c}\text { Rise } \\
\text { time }\end{array}$ & $\begin{array}{c}\text { Time for } \\
\text { speed } \\
\text { regulation }\end{array}$ & ripples & $\begin{array}{c}\text { Settling } \\
\text { time } \\
\text { before } \\
\text { changing } \\
\text { speed }\end{array}$ \\
\hline ANFIS & 0.4 & $0.3 \mathrm{sec}$ & no & $0.4 \mathrm{sec}$ \\
$\mathrm{sec}$ & $0.4 \mathrm{sec}$ & yes & $2.7 \mathrm{sec}$ \\
\hline $\begin{array}{c}\text { NARMA- } \\
\text { L2 } \\
{[13]}\end{array}$ & $\begin{array}{c}0.5 \\
\mathrm{sec}\end{array}$ & & & \\
\hline wap & 0.3 & $0.5 \mathrm{sec}$ & yes & $0.6 \mathrm{sec}$ \\
\hline sec & $6 \mathrm{sec}$ & $2 \mathrm{sec}$ & no & $6.4 \mathrm{sec}$ \\
\hline \hline
\end{tabular}


Table 6. Comparison results between proposed ANFIS controller and NARMA-L2 controller.

\begin{tabular}{|c|c|c|c|}
\hline $\begin{array}{c}\text { Control } \\
\text { strategies }\end{array}$ & $\begin{array}{l}\text { Settling } \\
\text { time after } \\
\text { changing } \\
\text { speed }\end{array}$ & Overshoot & Undershoot \\
\hline ANFIS & $0.3 \mathrm{sec}$ & No & No \\
\hline $\begin{array}{c}\text { NARMA- } \\
\text { L2 [13] }\end{array}$ & $0.4 \mathrm{sec}$ & Yes & No \\
\hline wap & $0.5 \mathrm{sec}$ & Yes & Yes \\
\hline was & $1.8 \mathrm{sec}$ & yes & no \\
\hline
\end{tabular}

Comparison between ANFIS and NARMA-L2 shows that there are more ripples in the speed response of NARMA-L2 controller than ANFIS until $\mathrm{t}=3 \mathrm{~s}$ and an over shoot at $\mathrm{t}=7 \mathrm{sec}$ [13].

\subsection{Simulation of ANFIS model compared with PSO based tuning of Fuzzy PI controller}

The proposed ANFIS is conducted again changing speed reference to a fixed value $(140 \mathrm{rad} / \mathrm{sec})$. The result is compared to [14], where V.Mahendiran et. al., proposed Particle Swarm Optimization (PSO) based tuning of Fuzzy PI controller to control of SEDCM under the various conditions like sudden change in load, sudden change in speed and sudden change in both [14] .Figure 14 shows speed response of ANFIS with constant reference speed and load change (5$25) \mathrm{Nm}$ at $\mathrm{t}=0.3 \mathrm{sec}$.

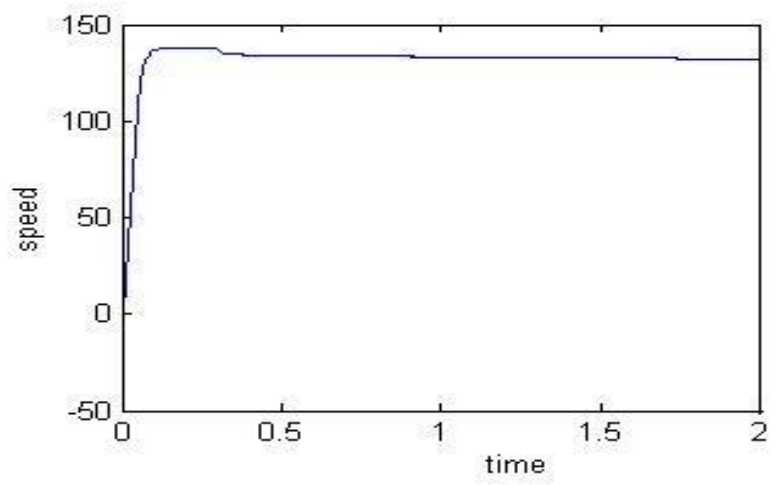

Fig 14 :speed response of the ANFIS controller.

Simulation results and comparisons prove that ANFIS performs with an acceptable response where rise time $=0.08$ se, while (PSO) based tuning of Fuzzy PI controller [14] has rise time $=0.7$ and has more ripples than ANFIS controller.

\subsection{Parameter variation effect on SEDCM}

One of the main problems with mathematical models of physical systems is that the parameters used in the models cannot be determined with absolute accuracy. Inaccurate parameters can arise from many different factors. The values of parameters may change with time or various effects. These differences existing between the actual system and system model is called uncertainty. However, the actual system parameters may change during operation or the input signal may increase. In these cases, the model is no longer representing the actual system and yet causes practical problems. Therefore, a robust controller is needed to stabilize these types of systems for the entire range of expected variations in the plant parameters [15].

Again , changing the speed reference as(120-160) $\mathrm{rad} / \mathrm{sec}$ at $\mathrm{t}=0.8 \mathrm{sec}$ and load from $(5-25) \mathrm{Nm}$ at $\mathrm{t}=1.5 \mathrm{sec}$. The electrical parameters $\mathrm{Ra}$ (armature winding resistance) is changed in the range from $(0.2 \Omega)$ to $(0.9 \Omega)$ to test the effect of parameter variation on SEDCM. Figure $(15,16)$ show the effect of parameter variation in PI and ANFIS controllers. Table 7,8. Illustrates comparison analysis between proposed ANFIS controller and PI controller.

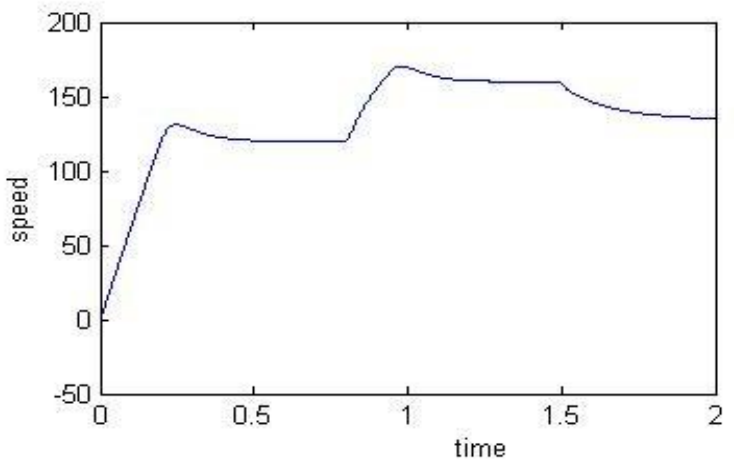

Fig, 15:Speed response of PI controller under effect of parameter variation $(\mathbf{R a})$.

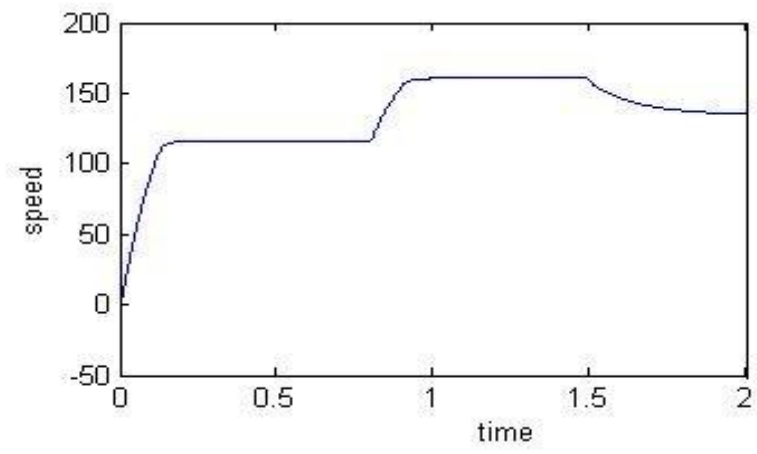

Fig, 16:Speed response of ANFIS controller under effect of parameter variation $(\mathbf{R a})$.

Table 7: Comparison results between proposed ANFIS controller and PI controller.

\begin{tabular}{||c|c|c|c|}
\hline $\begin{array}{c}\text { Control } \\
\text { strategies }\end{array}$ & $\begin{array}{c}\text { Rise } \\
\text { time }\end{array}$ & $\begin{array}{c}\text { Time for } \\
\text { speed } \\
\text { regulation }\end{array}$ & $\begin{array}{c}\text { Settling } \\
\text { time before } \\
\text { changing } \\
\text { load }\end{array}$ \\
\hline Conventional PI & $0.22 \mathrm{sec}$ & $0.28 \mathrm{sec}$ & $0.58 \mathrm{sec}$ \\
\hline ANFIS & $0.12 \mathrm{sec}$ & $0.12 \mathrm{sec}$ & $0.12 \mathrm{sec}$ \\
\hline
\end{tabular}


Table 8: Comparison results between proposed ANFIS controller and PI controller.

\begin{tabular}{|ccc|}
\hline $\begin{array}{c}\text { Control } \\
\text { strategies }\end{array}$ & $\begin{array}{c}\text { Settling time } \\
\text { after changing } \\
\text { load }\end{array}$ & Overshoot \\
Conventional PI & $0.23 \mathrm{sec}$ & Yes \\
ANFIS & $0.21 \mathrm{sec}$ & no \\
\hline
\end{tabular}

\subsection{Simulation of ANFIS model for step change in reference speed.}

The simulation results for step change in reference speed with the ANFIS speed controller are shown in figures 17,18. Figure 17 shows the simulated response for the step change in reference speed from 0 to $50 \%$ of the rated value at $0 \mathrm{sec}$ and $50 \%$ to $100 \%$ of the rated speed value at $1 \mathrm{sec}$ (where rated value of reference speed $=200 \mathrm{rad} / \mathrm{sec}$ ) and during this period, the load torque is $50 \%$ from the rated value of load torque (where rated value of load torque $=20 \mathrm{~N}$.m). Figure 1 shows the simulated response for the step change in reference speed from 0 to $75 \%$ of the rated value for $2 \mathrm{~s}$ with load torque changed from 0 to $100 \%$ of the rated value at $1 \mathrm{sec}$.

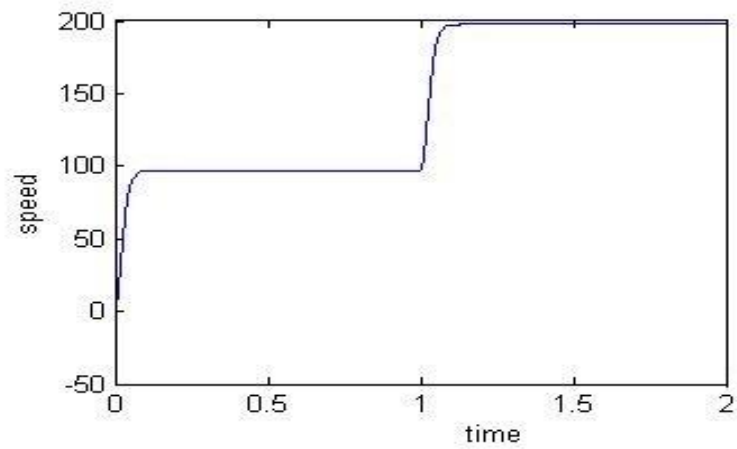

Fig 17: Simulated response for step change in reference speed from $50 \%$ of the rated value to the rated value at 1sec.

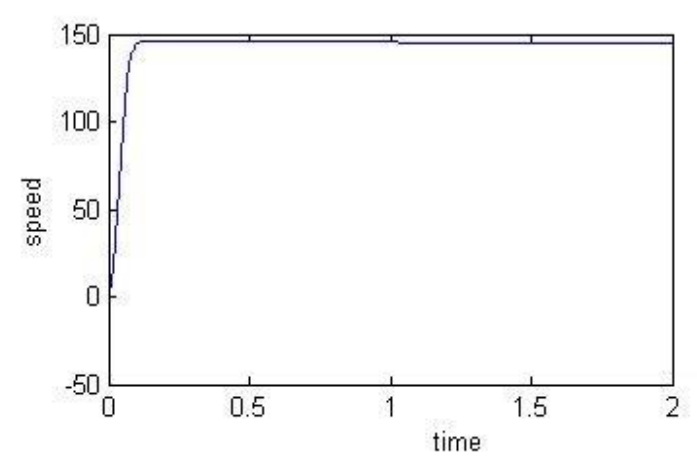

Fig 18: Simulated response for change in speed for a load change from 0 to $100 \%$ of the rated value at 1 sec.

The performance of the system with ANFIS speed controller is measured in terms of rise time and steady state error as shown in Table 9.
Table 9: Performance of ANFIS controller for step change of reference speed.

\begin{tabular}{|c|c|c|}
\hline $\begin{array}{c}\text { Step change in } \\
\text { Reference speed }\end{array}$ & $\begin{array}{c}\text { Rise time } \\
\text { In sec }\end{array}$ & $\begin{array}{c}\text { Steady state error } \\
\text { In \% }\end{array}$ \\
\hline $\begin{array}{c}0 \text { to } 50 \% \text { of } \\
\text { rated value }\end{array}$ & 0.07 & 0.3 \\
\hline $\begin{array}{c}50 \text { to } 100 \% \text { of } \\
\text { rated value }\end{array}$ & 0.08 & 0.3 \\
\hline $\begin{array}{c}0 \text { to } 75 \% \text { of } \\
\text { rated value }\end{array}$ & 0.08 & 0.4 \\
\hline
\end{tabular}

From this simulation results as shown in Table 9, it is inferred that diffrent range of speed control is possible by means of ANFIS controller. The results are obtained without peak overshoot and with negligible steady state error.

\section{CONCLUSIONS}

Speed controller system based on (ANFIS) Controller has been successfully developed using MATLAB (2009) to control the speed of a separately excited DC motor. This paper lies in the application of (ANFIS) controller to control a SEDCM. This paper also discusses the effect of parameter variations on armature resistance of SEDCM and its impact on speed. The performance of the system has been compared with conventional PI controller, fuzzy self-tuning PID controller [12], Neural Network (NN) speed controller [13], and PSO based fuzzy PI controller[14]. An improved speed response is achieved with the ANFIS than the other techniques mentioned. The performance is tested by simulations. There is a reduction in number of ripples as well as steady state error and rise time also, no overshoot appears. Moreover ANFIS controller regulates the speed in time less than previously mentioned controllers.

Actually, the proposed ANFIS speed controller improves the performance in both transient and steady state response in comparison to the other controllers.

\section{ACKNOWLEDGMENTS}

We are very grateful to the editor and reviewers for their valuable comments and suggestions to help improving this work.

\section{REFERENCES}

[1] Jang J. S. R. "Adaptive network based fuzzy inference systems". IEEE Transactions on systems man and cybernetics 1993,pp. 665-685.

[2] J. Santana, J. L. Naredo, F. Sandoval, I. Grout, and O. J. Argueta, "Simulation and construction of a speed control for a DC series motor," Mechatronics, vol. 12, issues 910, Dec.2002, pp. 1145-1156.

[3] M. D. Minkova, D. Minkov, J. L. Rodgerson, and R. G. Harley, "Adaptive neural speed controller of a dc motor," Electric Power Systems Research, vol. 47, issue 2, 15 Oct. 1998, pp. 123-132. 
[4] A. M. N. Lima, J. H. F. Cavalcanti, and G. S. Deep, "Online training of adaptive neural network controllers", 20th Int. Conf. Ind. Electronics, Control and Instrumentation, vol. 2, 5-9 Sep. 1994, pp. 1392-1395.

[5] G.MadhusudhanaRao1,.B.V.SankerRam " A Neural Network Based Speed Control for DC Motor "International Journal of Recent Trends in Engineering, Vol 2, No.6, November 2009

[6] A.S.Poznyak, "Adaptive Tracking for DC-Derivative Motor Based on Motions Forgetting", Computation system, Vol.4, No.3, 2001, pp.205-212.

[7] M.H.Rashid, "Power Electronics", Prentic-Hall of India, Newdelhi, 1994.

[8] The Mathworks Inc., MATLAB/SimPowerSystems Demos/ Chopper-fed DC Motor Drive version 2009

[9] Moleykutty George, "Speed Control of Separately Excited DC Motor",Faculty of Engineering and Technology, Multimedia University Melaka Campus, 75450 Melaka, Malaysia,2008.

[10] Lin C. T., Lee C. S. G. Neural fuzzy systems: A neurofuzzy synergism to intelligent systems. Upper Saddle River, Prentice-Hall, 1996.
[11] A. Miloudi1, Eid A. Al -Radadi and A. D. Draou , "A Variable Gain PI Controller Used for Speed Control of a Direct Torque Neuro Fuzzy Controlled Induction Machine Drive", Turk J Elec Engin, Vol.15, No.1 2007,pp. 210-215.

[12] M.M.F. Algreer , R.M.Kuraz"Design "Fuzzy Self Tuning of PID Controller for Chopper-Fed DC Motor" Drive"AlRafidain Engineering,Vol.16 ,No.2,r 2008.

[13] Moleykutty George , "Speed Control of Separately Excited DC Motor", American Journal of Applied Sciences, Volume: 5,no. 3, 2008,

[14] T.V.Mahendiran1, P.Thangam et.al.," A Comparative Study on Non Linear Drive Control for Separately Excited DC Motor Using Fuzzy Logic Controller, Fuzzy PI Controller and PSO Tuned Fuzzy PI Controller ", International Journal of Research and Reviews in Electrical and Computer Engineering ,Vol. 1, No. 1, March 2011

[15] S.E. Hamamci,, M. Koksal "Robust Control of a DC Motor by Coefficient Diagram Method", MED'01 The 9th Mediterranean Conference on Control and Automation, vol. 148, no. 1, Jan. 2001, pp. 85-90 